\title{
Prevalence of Social Anxiety Disorder among Medical Students from Six Medical Schools in Khartoum State
}

\author{
Hazeem Abdeljaleel Suleiman, Sara Ahmed Elamin², Abdalaziz Awad \\ Alobeid ${ }^{3}$, and Wegdan Elshame Altaib ${ }^{4}$ \\ ${ }^{1}$ Medical student, Ain Shams University, Cairo, Egypt \\ ${ }^{2}$ Medical student, Omdurman Al-Ahlia University, Omdurman, Sudan \\ ${ }^{3}$ Medical student, Omdurman Islamic University, Omdurman, Sudan \\ ${ }^{4}$ Medical student, Al Neelain University, Khartoum, Sudan
}

ORCID:

Hazeem Abdeljaleel Suleiman: https://orcid.org/0000-0002-4812-7866

Abdalaziz Awad Alobeid: https://orcid.org/0000-0003-3739-3031

Sara Ahmed Elamin: https://orcid.org/0000-0002-9414-4544

Wegdan Elshame Altaib: https://orcid.org/0000-0002-4541-1327

Corresponding Author: Hazeem Abeljaleel Suleiman; Medical student, Ain Shams University, Cairo, Egypt. email:

160994@med.asu.edu.eg

Received 5 April 2021

Accepted 16 May 2021

Published 30 June 2021

Production and Hosting by Knowledge E

(c) Hazeem Abeljaleel

Suleiman et al. This article is distributed under the terms of the Creative Commons

Attribution License, which permits unrestricted use and redistribution provided that the original author and source are credited.

Editor-in-Chief:

Prof. Mohammad A. M. Ibnouf

\section{Abstract}

Background: Social anxiety disorder (social phobia) is a type of anxiety disorder which is characterized by significant anxiety and discomfort about being embarrassed, humiliated, rejected, or looked down on in social interactions. Although it affects about $30 \%$ of adults worldwide at some point in their lives, lifetime social anxiety disorder affects only about $4 \%$ of the world population. People with this disorder experience extreme fear of social interactions (e.g., public speaking and meeting new people). This anxiety affects daily functions and lasts at least six months. They may also experience strong physical symptoms like rapid heart rate, nausea, vomiting, and full-blown attacks. Social phobia can be treated by a combination of psychotherapy and medical treatment (e.g., anti-anxiety, antidepressants, and beta-blockers).

Methods: This study was conducted using the Arabic SPIN and a group of questions to assess the associated factors, complications, and sociodemographic determinate of social anxiety disorder and included a total of 375 medical students from different universities and educational years.

Results: The overall prevalence of social anxiety disorder among our participants was $61.3 \%$, of which $19.2 \%$ had mild, $21.6 \%$ moderate, $10.9 \%$ severe, and $9.6 \%$ had very severe SAD. There was a significant difference regarding self-esteem, academic achievement, and drug addiction between students with social phobia and students with no social phobia.

Conclusion: Social phobia is quite prevalent among Sudanese medical students, particularly the severe form of the disorder with no significant gender differences. It seems to affect self-esteem and academic achievement and can be associated with drug addiction.

Keywords: social phobia, prevalence, medical students, Sudanese

\section{S OPEN ACCESS}




\section{Introduction}

Social anxiety disorder (SAD; also known as social phobia) is a type of anxiety disorder which is characterized by significant anxiety and discomfort about being embarrassed, humiliated, rejected, or looked down on in social interactions [1].

Anxiety disorders are common and affect about $30 \%$ of adults worldwide at some point in their lives [1]. However, lifetime SAD affects only about $4 \%$ of the world population [2]. Interestingly, SAD intends to show a direct relationship with average country income as its mean prevalence is shown to be $5.5 \%$ in high-income countries and $6.4 \%$ in the regions of America while it is $1.6 \%$ in low- income countries and $1.2 \%$ in the regions of Africa and Middle East [2]. These differences can be explained by differences in regional diagnostic thresholds in higher-income countries, poor statistical services in middle- and low-income countries, and higher demands for social performance in highincome countries may also play a role.

People with this disorder experience extreme fear of social interactions (e.g., public speaking and meeting new people). This anxiety affects daily functions and lasts at least six months [1]. Patients with social phobia may also experience strong physical symptoms. Common examples are rapid heart rate, nausea, and vomiting, however, they may also experience full-blown attacks when confronting a feared situation [3]. Social phobia can be treated by a combination of psychotherapy, group therapy, and medical treatment (e.g., anti-anxiety, antidepressants, and beta-blockers) [4].

Many studies have been conducted to evaluate social phobia prevalence, risk factors, complications, and prevention efforts in different countries. However, to the best of our knowledge, studies addressing social phobia among Sudanese medical students are scarce. Therefore, the current study was conducted to measure the prevalence of social phobia in a group of medical students from six medical schools in Khartoum, Sudan. This study will help the healthcare organizations in Sudan to take social phobia and anxiety disorders in general as a real threat to patient's quality of life and to put suitable intervention for them. Moreover, the study is quite important to medical students as they need to know about social phobia and how to manage it because their future career will inevitably require a lot of social interactions, presentations at clinical meetings and at large-scale academic and administrative events regardless of their chosen specialty. 


\section{Materials and Methods}

\subsection{Study population and design}

This cross-sectional study was conducted at the Faculty of Medicine of the six chosen universities. A convenient sample of 375 was calculated using SAD prevalence among university students in Saudi Arabia that equaled 60\% [7]. The confidence interval was 95\%. The sample size was calculated using EPI Info 2002 program.

\subsection{Study tools}

Data from December 15, 2020 to January 15, 2021 were collected using an online selfadministrated questionnaire that consisted of four sections.

Section one included sociodemographic characteristics (gender, age, study year, and university).

Section two included the Arabic version of the social phobia inventory (SPIN) to assess the prevalence of SAD and its degree among participants. The Arabic SPIN was found to have excellent internal consistency and good test-re-test reliability. A cut-off score of 23 distinguished well between those with social phobia and those without. It was reliable and valid for the screening the population [5].

Section three included factors that can be associated with SAD, such as family history of similar conditions, suffering bullying in childhood, and presence of diseases that can be associated with stigma like congenital anomalies (e.g., on the face) and diseases causing involuntary movements (e.g., in Parkinsonism).

Section four included the expected complications of SAD, such as low selfconfidence, low academic achievement, drug addiction, and suicide attempts.

\subsection{Statistical analysis}

The collected data were revised, coded, entered into a PC, and analyzed using the SPSS version 16. The collected data were analyzed according to the type of variables. Quantitative variables were presented by their mean and standard deviation and analyzed using $t$-test. Qualitative variables were presented by frequency and analyzed using the Chi-square test

$P$-value $<0.05$ was considered as significant. 


\section{Results}

In total, 375 students responded to the questionnaire with a response rate of $28 \%$. This low rate reflects the low awareness of SAD among Sudanese medical students.

Of the 375 participants, 123 (23.8\%) were males and 252 (67.8\%) females; 350 (93.3\%) of them were in the 18-23 years and $25(6.7 \%)$ in the $24-30$ years age groups with a mean age of 21.4 years (SD = 1.46); $264(70.4 \%)$ of them were in the first three levels and $111(29.6 \%)$ were in the fourth and fifth levels (Table 1).

Moreover, 94 (25.1\%) participants were from Omdurman Islamic University (OIU), 70 (18.7\%) from Omdurman Al-Ahlia University (OAU), 67 (17.9\%) from Khartoum University, 57 (15.2\%) from Al-Zaiem Alzhari University (AAU), 69 (18.4\%) from Al-Nilain University (NU), and 18 (4.7\%) from Sudan University of Science and Technology (SUST) (Table 1).

In total, 230 (61.3\%) students were found to have SAD, of which 72 (19.2\%) had mild, 81 (21.6\%) moderate, 41 (10.9\%) severe, and 36 (9.6\%) had very severe SAD (Figure 1). Out of the 123 males, 73 (59.3\%) had SAD and out of the 252 females, 157 (62.3\%) had SAD (Figure 2). Moreover, $65.6 \%$ of Khartoum University students, $65.2 \%$ of NU students, $64.9 \%$ of OIU students, $59.6 \%$ of AAU students, $52.8 \%$ of OAU students, and $50 \%$ of SUST students had SAD (Figure 2 ).

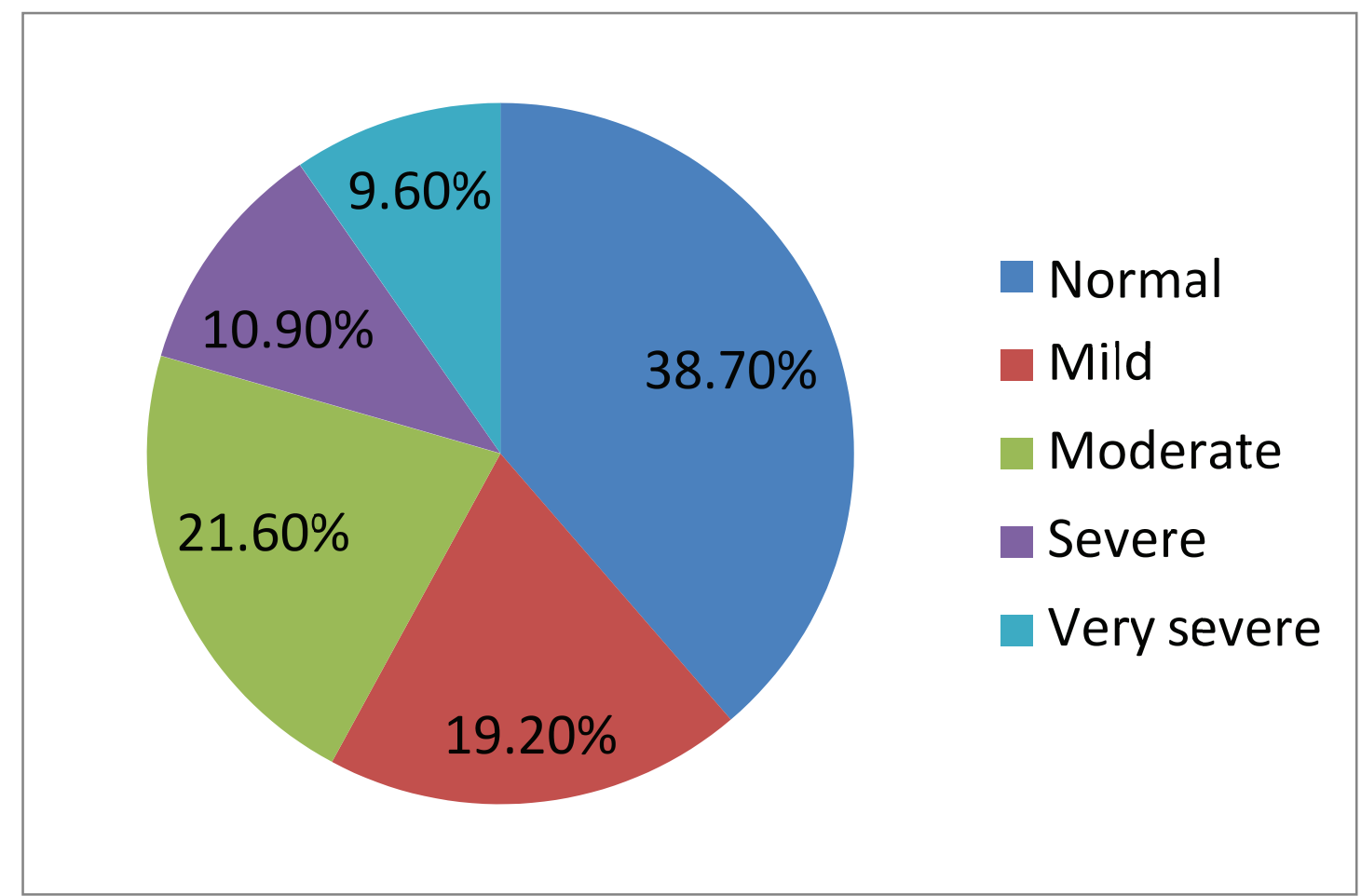

Figure 1: Prevalence of SAD among participants. 


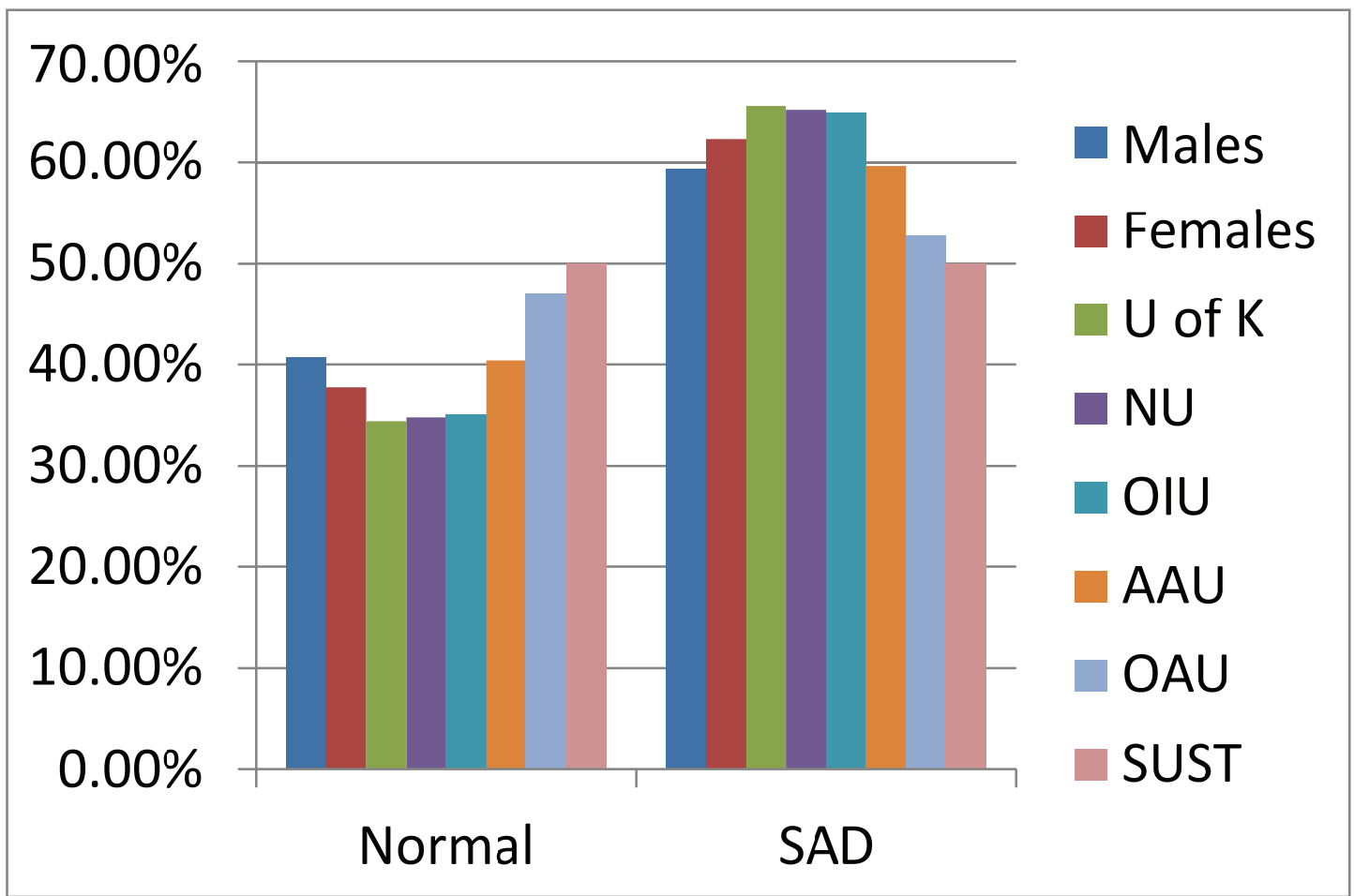

Figure 2: Prevalence of SAD by gender and university.

TABLE 1: Sociodemographic characteristics.

\begin{tabular}{l} 
Sex \\
Age (yr) \\
University \\
\hline \\
\hline Level
\end{tabular}

\begin{tabular}{|c|}
\hline Males \\
\hline $123(32.8 \%)$ \\
$18-23$ \\
$350(93.3 \%)$ \\
Khartoum \\
Al-Nilain \\
\hline Omdurman Islamic university \\
\hline Omdurman Al- Ahlia university \\
\hline Al-Zaiem Alzhari \\
\hline Sudan university \\
$1^{\text {st }}-3^{\text {rd }}$ \\
\hline 264 (70.4\%)
\end{tabular}

\begin{tabular}{|c|}
\hline Females \\
\hline $252(67.2 \%)$ \\
$24-30$ \\
$25(6.7 \%)$ \\
$67(17.9 \%)$ \\
$69(18.4 \%)$ \\
$94(25.1 \%)$ \\
$70(18.7 \%)$ \\
$57(15.2 \%)$ \\
$18(4.7 \%)$ \\
4 th-5th \\
\hline $111(29.6 \%)$ \\
\hline
\end{tabular}

Initial analysis showed that $184(80 \%)$ students with SAD considered themselves shy in comparison to 40 (27.6\%) students with no SAD; 148 (64.3\%) students with SAD had low self-esteem in comparison to 25 (17.2\%) students with no SAD; 90 (39.1\%) students with SAD had high academic grades (B or higher) in comparison to 80 (55.1\%) with no SAD. These differences were found to be statistically significant ( $p$-value $<0.05$ ) (Table 2). 
TABLE 2: Associated factors of SAD.

\begin{tabular}{l|c|c|c} 
& Normal & $\begin{array}{c}\text { Social anxiety } \\
\text { Disorder }\end{array}$ & P-value \\
\hline $\begin{array}{l}\text { Family history of social anxiety disorder } \\
\text { Being bullied in childhood }\end{array}$ & $N=4(2.75 \%)$ & $N=6(2.6 \%)$ & 0.153 \\
\hline $\begin{array}{l}\text { Are you a shy person? } \\
\text { Presence of congenital anomalies }\end{array}$ & $N=64(44.1 \%)$ & $N=128(55.6 \%)$ & 0.120 \\
\hline $\begin{array}{l}\text { Presence of diseases causes involuntary } \\
\text { movements }\end{array}$ & $N=3(27.6 \%)$ & $N=184(80 \%)$ & 0.000 \\
\hline $\begin{array}{l}\text { Suffering low self-esteem } \\
\text { Suicidal attempts }\end{array}$ & $N=25(17.2 \%)$ & $N=11(4.8 \%)$ & 0.435 \\
\hline $\begin{array}{l}\text { Drug addiction } \\
\text { High academic achievement (B or higher) }\end{array}$ & $N=11(7.6 \%)$ & $N=8(3.5 \%)$ & 0.178 \\
\hline
\end{tabular}

TABLE 3: Poisson regression analysis of associated factors of SAD.

\begin{tabular}{|c|c|c|c|c|}
\hline \multicolumn{5}{|c|}{ Poisson Regression analysis } \\
\hline Items & $P$-value & $\begin{array}{l}\text { Estimates of } \\
\text { coefficients }\end{array}$ & $\begin{array}{l}\text { 95\% Wald } \\
\text { confidence } \\
\text { interval }\end{array}$ & $\begin{array}{c}\text { 95\% Wald } \\
\text { confidence } \\
\text { interval for Exp } \\
\text { (B) }\end{array}$ \\
\hline $\begin{array}{l}\text { Family history of social } \\
\text { anxiety disorder }\end{array}$ & $P=0.880$ & 0.057 & $-0.600-0.429$ & $0.549-1.536$ \\
\hline $\begin{array}{l}\text { Being bullied at } \\
\text { childhood? }\end{array}$ & $P=0.905$ & 0.011 & $-0.151-0.184$ & $0.860-1.202$ \\
\hline Are you a shy person? & $P<0.001$ & 1.234 & $0.059-0.443$ & $1.061-1.557$ \\
\hline $\begin{array}{l}\text { Presence of congenital } \\
\text { anomalies }\end{array}$ & $P=0.805$ & -0.003 & $-0.390-0.431$ & $0.677-1.539$ \\
\hline $\begin{array}{l}\text { Presence of diseases } \\
\text { causes involuntary } \\
\text { movements }\end{array}$ & $P=0.368$ & 0.182 & $-0.371-0.671$ & $0.690-1.975$ \\
\hline $\begin{array}{l}\text { Suffering low self } \\
\text {-esteem }\end{array}$ & $P<0.001$ & 0.626 & $-0.035-0.337$ & $0.966-1.401$ \\
\hline Suicidal attempts & $P=0.390$ & 0.260 & $-0.258-0.405$ & $0.772-1.499$ \\
\hline Drug addiction & $P=0.037$ & 0.079 & $-0.369-0.255$ & $0.692-1.290$ \\
\hline $\begin{array}{l}\text { High academic } \\
\text { achievement ( } \mathrm{B} \text { or } \\
\text { higher) }\end{array}$ & $P=0.046$ & 0.22 & $-0.218-0.117$ & $0.804-1.124$ \\
\hline
\end{tabular}

Poisson regression analysis was done for further assessing the relation between the associated factors and social phobia; however, except for drug addiction ( $p=0.037)$, no more significant differences between the two groups were found (Table 3 ).

\section{Discussion}

The prevalence of SAD in the present study was $61.3 \%$ which is lower than the other Sudanese study that showed a $78.4 \%$ prevalence of anxiety [6] but is very similar to a 
study conducted at King Khalid University in Saudi Arabia that showed a prevalence of $60 \%$ [7]. Furthermore, although a high prevalence (92.1\%) was reported in a study conducted in Saudi Arabia on 1,447 medical students [8], a lower prevalence was reported in a study in Norway [9] and England [10]. These differences can be attributed to the use of different evaluating tools, and gender and cultural differences between different populations may play a role.

In our study, there was no significant difference in the prevalence of SAD between males (59.3\%) and females (62.3\%). These findings were found to be lower than the Saudi study which showed a prevalence of $92.8 \%$ in males and $91.7 \%$ in females [8] and higher than the findings of an Indian study that showed a female prevalence of $16.28 \%$ and a male prevalence of $10.97 \%$ [11].

Among students who had SAD, the most common form was moderate SAD (21.6\%), followed by mild and severe (19.2 and 10.9\%, respectively), and very severe SAD (9.6\%). These findings are higher than the findings of a study conducted in Ethiopia [12].

Our findings show that students with SAD tend to get significantly higher grade than students with no SAD ( $p=0.001)$, which is consistent with the findings of King Khalid University study [7]. However, it contrasts with another study conducted in Iran [13].

Additionally, our findings show a significantly positive association between SAD and drug abuse, which is consistent with the findings of a systematic review published in the American Journal of Drug and Alcohol Abuse [14].

\section{Study limitations}

Selective bias caused using convenient sampling. Convenience sampling was used due to the lack of interest of students to participate in the study, which reflects the low awareness about SAD, and this selection bias could have underestimated the true prevalence and severity of SAD.

\section{Conclusion}

There was a moderate grade of social phobia between participants with no significant gender differences, and social phobia seems to affect self-esteem and academic achievement and can be associated with drug addiction. 


\section{Recommendations}

(i) We recommend implanting programs to raise awareness about social phobia, especially among medical students. These programs can include defining illness and ways to cope with stress, reducing symptoms, and encouraging visiting a psychiatrist.

(ii) We encourage more future studies that avoid our study limitations and include a wider population than medical students. Also, there is a need for more studies focusing on therapeutic interventions, pre-enrolment assessment of medical students, and exploration of the link between both underachievement and drug addiction and SAD.

\section{Acknowledgements}

The authors are grateful to the medical students for their cooperation in the study.

\section{Ethical Considerations}

Participation was voluntary and confidentiality was assured to all respondents. They were informed about the study's objectives and that the data collected would be used only for the stated research purposes.

\section{Competing Interests}

None.

\section{Availability of Data and Materials}

The study materials are available from the corresponding author upon request.

\section{Funding}

The author received no funding for this research. 


\section{References}

[1] American Psychiatric Association. (n.d.). What Are Anxiety Disorders? Retrieved from: https://www.psychiatry.org/patients-families/anxiety-disorders/what-areanxiety-disorders

[2] Stein, D. J., Lim, C. C. W., Roest, A. M., et al. (2017). The cross-national epidemiology of the social anxiety disorder: data from the world Mental Health Survey initiative. BMC Medicine, vol. 15, article 143.

[3] National Institute of Mental Health. (n.d.). Social Anxiety Disorder: More Than Just Shyness. Retrieved from: https://www.nimh.nih.gov/health/publications/socialanxiety-disorder-more-than-just-shyness/

[4] American Depression \& Anxiety Association. (n.d.). Understand the Facts - Social Anxiety Disorder. Retrieved from: https://adaa.org/understanding-anxiety/socialanxiety-disorder/.

[5] Ragheb, M., Ramy, H., Hussein, H., et al. (2007). Psychometric properties of the Arabic version of social phobia inventory (SPIN). Current Psychiatry, vol. 14, no. 1, pp. 36-44.

[6] Dafaalla, M., Farah, A., Bashir, S., et al. (2017). Depression, anxiety, and stress in Sudanese medical students: a cross sectional study on role of quality of life and social support. American Journal of Educational Research, vol. 4, no. 13, pp. 937942.

[7] Alqarni, A. A., Zalaa, M. A., El-Hadad, A. A., et al. (2017). Prevalence of social phobia among Saudi medical students. Medical Journal of Cairo University, vol. 85, no. 2, pp. 657-661.

[8] Alkhalifah, A. K., Alsalameh, N. S., Alhomaidhy, M. A., et al. (2017). Prevalence of social phobia among medical students in Saudi Arabia. The Egyptian Journal of Hospital Medicine, vol. 69, no. 5, pp. 2412-2416.

[9] Kjeldstadli, K., Tyssen, R., Finset, A., et al. (2006). Life satisfaction and resilience in medical school-a six-year longitudinal, nationwide and comparative study. BMC Medical Education, vol. 6, no. 48, pp. 1-8.

[10] Laidlaw, A. H. (2009). Social anxiety in medical students: implications for communication skills teaching. Medical Teacher, vol. 31, no. 7, pp. 649-654.

[11] Jogdande, A. J. and Gupta, A. (2017). Social anxiety disorder in medical students: socio-demographic correlates. International Journal of Community Medicine and Public Health, vol. 4, no. 9, pp. 3293-3296. 
[12] Desalegn, G. T., Getinet, W., and Tadie, G. (2019). The prevalence and correlates of social phobia among undergraduate health science students in Gondar, Gondar Ethiopia. BMC Research Notes, vol. 12, article 438.

[13] Mazhari, S. H., Ekhlaspour, M., and Banazadeh, N. (2014). Social phobia and its association with academic performance among student of Kerman University of Medical Sciences, Iran. Journal of Strides in Development of Medical Education, vol. 11, no. 2, pp. 227-235.

[14] Lemyre, A., Gauthier-Légaré, A., and Bélanger, R. E. (2018). Shyness, social anxiety, social anxiety disorder, and substance use among normative adolescent populations: a systematic review. The American Journal of Drug and Alcohol Abuse, vol. 45, no. 3, pp. 1097-9891. 